\title{
Chemotherapy Order Entry by a Clinical Support Pharmacy Technician in an Outpatient Medical Day Unit
}

\author{
Heather Neville, Larry Broadfield, Claudia Harding, Shelley Heukshorst, Jennifer Sweetapple, and \\ Megan Rolle
}

\begin{abstract}
Background: Pharmacy technicians are expanding their scope of practice, often in partnership with pharmacists. In oncology, such a shift in responsibilities may lead to workflow efficiencies, but may also cause concerns about patient risk and medication errors.
\end{abstract}

Objectives: The primary objective was to compare the time spent on order entry and order-entry checking before and after training of a clinical support pharmacy technician (CSPT) to perform chemotherapy order entry. The secondary objectives were to document workflow interruptions and to assess medication errors.

Methods: This before-and-after observational study investigated chemotherapy order entry for ambulatory oncology patients. Order entry was performed by pharmacists before the process change (phase 1) and by 1 CSPT after the change (phase 2); order-entry checking was performed by a pharmacist during both phases. The tasks were timed by an independent observer using a personal digital assistant. A convenience sample of 125 orders was targeted for each phase. Data were exported to Microsoft Excel software, and timing differences for each task were tested with an unpaired $t$ test.

Results: Totals of 143 and 128 individual orders were timed for order entry during phase 1 (pharmacist) and phase 2 (CSPT), respectively. The mean total time to perform order entry was greater during phase 1 (1:37 min versus $1: 20 \mathrm{~min} ; p=0.044)$. Totals of 144 and 122 individual orders were timed for order-entry checking (by a pharmacist) in phases 1 and 2, respectively, and there was no difference in mean total time for order-entry checking (1:21 min versus $1: 20 \mathrm{~min} ; p=0.69)$. There were 33 interruptions not related to order entry (totalling 39:38 min) during phase 1 and 25 interruptions (totalling 30:08 $\mathrm{min}$ ) during phase 2. Three errors were observed during order entry in phase 1 and one error during order-entry checking in phase 2; the errors were rated as having no effect on patient care.

Conclusions: Chemotherapy order entry by a trained CSPT appeared to be just as safe and efficient as order entry by a pharmacist. Changes in pharmacy technicians' scope of practice could increase the amount of time available for pharmacists to provide direct patient care in the oncology setting.

\section{RÉSUMÉ}

Contexte : Les techniciens en pharmacie élargissent leur champ de pratique, souvent en partenariat avec les pharmaciens. En oncologie, un tel changement dans les responsabilités pourrait conduire à une optimisation de l'organisation du travail, mais il peut aussi soulever des inquiétudes au sujet des risques pour le patient et des erreurs de médicaments.

Objectifs : L’objectif principal était de comparer le temps passé à la saisie d'ordonnances et à la vérification de cette saisie avant et après avoir formé un technicien en pharmacie dédié au soutien clinique (TPDSC) à la saisie d'ordonnances de chimiothérapie. Les objectifs secondaires étaient de répertorier les interruptions de travail et d'évaluer les erreurs de médicaments.

Méthodes : La présente étude observationnelle avant-après s'est intéressée à la saisie d'ordonnances de chimiothérapie pour les patients ambulatoires en oncologie. La saisie d'ordonnances était réalisée par des pharmaciens avant le changement de procédé (phase 1), puis, après le changement (phase 2), un TPDSC en avait la responsabilité. Un pharmacien vérifiait la saisie d'ordonnances au cours des deux phases. Les tâches étaient chronométrées par un observateur indépendant à l'aide d'un assistant numérique personnel. Un échantillon de commodité de 125 ordonnances était souhaité pour chaque phase. Les données ont été consignées dans un tableur Excel de Microsoft et les écarts de temps pour chaque tâche ont été évalués à l'aide d'un test $t$ pour échantillons indépendants.

Résultats : Au total, on a chronométré le temps de saisie pour 143 ordonnances à la phase 1 (pharmacien), puis de 128 ordonnances pour la phase 2 (TPDSC). Le temps total moyen nécessaire pour saisir une ordonnance était plus long au cours de la phase 1 ( 1 min $37 \mathrm{~s}$ contre $1 \min 20 s ; p=0,044$ ). Au total, on a chronométré la vérification (réalisée par un pharmacien) de saisie pour 144 ordonnances à la phase 1 et 122 ordonnances à la phase 2 . Aucune différence notable n'a été relevée dans le temps total moyen de vérification $(1 \mathrm{~min} 21 \mathrm{~s}$ contre $1 \mathrm{~min} 20 \mathrm{~s}$; $p=0,69)$. On a dénombré 33 interruptions sans lien à la saisie d'ordonnances (totalisant $39 \mathrm{~min} 38 \mathrm{~s}$ ) au cours de la phase 1 et 25 interruptions (totalisant 30 min et $8 \mathrm{~s}$ ) durant la phase 2. Trois erreurs à la saisie d'ordonnances ont été observées pendant la phase 1 et une erreur à la vérification de la saisie d'ordonnances pendant la phase 2 ; ces erreurs ont été jugées sans effet sur les soins aux patients. 
Keywords: pharmacy technician, clinical support, chemotherapy order entry, time- and- motion studiese

Can J Hosp Pharm. 2016;69(3):202-8
Conclusions : La saisie d'ordonnances de chimiothérapie par un TPDSC formé semblait être tout aussi sûre et efficiente que si elle était réalisée par un pharmacien. Les changements apportés au champ de pratique des techniciens en pharmacie pourraient accroître le temps dont disposent les pharmaciens pour prodiguer des soins directs aux patients en oncologie.

Mots clés : technicien en pharmacie, soutien clinique, saisie d'ordonnances de chimiothérapie, études des temps et mouvements

\section{INTRODUCTION}

$\mathrm{P}$ atients receiving cancer chemotherapy are thought to be at higher risk of serious, potentially devastating errors than patients receiving other medications. ${ }^{1,2}$ Cancer chemotherapy drugs often have a narrow therapeutic index, are toxic even at usual doses, and have complex dosing regimens; in addition, this patient population may be vulnerable because of age or previous cancer treatment. ${ }^{1,2}$ Chemotherapy medication orders reviewed by trained nurses, pharmacists, and physicians have had documented error rates up to 3\%. ${ }^{3,4}$ Errors included incorrect volumes for prehydration, missing premedication orders, and doses that were too high because they were not adjusted on the basis of the patient's clinical status. ${ }^{3,4}$ Oncology pharmacy services employ numerous strategies to decrease the risk of harm, such as use of preprinted orders and/or computerized provider order entry, staff certification in the preparation of chemotherapy, written policies and procedures for the safe handling of hazardous drugs, evidence-based treatment guidelines, and adherence with current standards of practice for providing pharmaceutical care to patients. ${ }^{5}$ A vital component of the oncology pharmacy service is the teamwork between oncology pharmacists and pharmacy technicians.

Pharmacy technicians' roles have expanded in Canada and other countries. The expanded roles have included obtaining medication histories in the emergency department or the preoperative clinic. ${ }^{6,7}$ Pharmacy technicians have also been successfully deployed directly on nursing units to assist pharmacists with activities such as medication reconciliation, order entry, screening for discharge counselling ${ }^{8}$ and obtaining patients' clinical data for review by a pharmacist. ${ }^{9}$ The clinical support pharmacy technician (CSPT) in oncology is an innovative position that represents a creative solution to the increasing pressures faced by oncology pharmacy services. ${ }^{10,11}$ In the oncology setting, the technician gathers predetermined clinical data from various sources (e.g., laboratory results and the patient's health record), completes documentation on request forms for drug funding, performs calculations, obtains best possible medication histories, and performs other defined technical tasks. ${ }^{11}$ The goal is to allow pharmacy technicians to work to their full scope, thereby freeing up time for the clinical pharmacist to provide more direct patient care services.

In February 2010, the Capital District Health Authority (Capital Health) in Halifax, Nova Scotia, created the position of oncology CSPT for the pharmacy satellite in the Medical Day Unit (MDU). The CSPT role was created in response to the steady increase in cancer therapy workload because of increased numbers of both patients and clinical trials, which had resulted in expanded lines of therapy being offered to each patient. The preparation of chemotherapy orders involved multiple steps of order screening, verification, order entry, order-entry checking, product preparation, and product checking; these tasks were performed by various pharmacy staff in the MDU and in a busy centralized chemotherapy preparation room. To improve efficiency and allow staff members to work to their full scope of practice, the CSPT was trained and certified in 2012 to enter chemotherapy orders in the MDU. The training consisted of reading relevant policies; practising order entry with a pharmacist, for a minimum of 10 days with a minimum of 100 patient order sets; and being tested by a different pharmacist, with a required score of $100 \%$.

The objective of this study was to compare the time spent on order entry and order-entry checking before and after the CSPT was trained to perform chemotherapy order entry. Secondary objectives were to document workflow interruptions and to assess any errors identified during the order entry and order-entry checking processes.

\section{METHODS}

This prospective before-and-after study evaluated the efficiency and safety of a new chemotherapy order entry and checking process for oncology patients at the MDU. This study was considered a quality assurance project, and ethics approval was waived by the Capital Health Research Ethics Board on September 30, 2011.

\section{Setting and Processes}

Outpatient treatment for hematological malignancies is performed in the MDU of Capital Health, an adult tertiary care 
regional health centre. Chemotherapy order review and pharmaceutical care are provided to patients by an oncology pharmacist in the MDU, with support from the CSPT.

The CSPT role initially included the technical aspects of verifying the completeness of pharmacy patient records by checking against the MDU record, generating patient treatment lists for the chemotherapy room, maintaining electronic patient profiles for the pharmacy, starting new patient profiles by accessing information from the institution's electronic health records, verifying eligibility for drug coverage under the provincial cancer drug program, and ensuring that the appropriate paperwork was completed. Patient-centred activities included screening chemotherapy orders for MDU patients, obtaining laboratory results, gathering patient counselling materials, and producing patient medication calendars for chemotherapy protocols. The CSPT was also responsible for screening telephone calls. The MDU pharmacist verified and approved chemotherapy orders, monitored patients for side effects, counselled patients, and responded to questions from nurses and physicians.

The CSPT responsibilities were subsequently expanded to include chemotherapy order entry in the pharmacy information system for all MDU patients, with order entry being performed after the pharmacist had verified that the order was appropriate for the patient. Order entry includes selecting the correct patient, entering allergy status, selecting the correct billing plan to charge the medication, and correctly entering all parts of the prescription, such as drug or predefined order group, physician, dose, volume, and expiry date. After successfully completing the training program and certification, the CSPT (S.H.) began entering chemotherapy orders in March 2012.

Before the process change, chemotherapy orders for Capital Health were entered, prepared, and checked in a centralized chemotherapy room with 2 biological safety cabinets staffed by 3 pharmacy technicians and 2 oncology pharmacists (see Figure 1). All MDU chemotherapy orders were first screened by the CSPT in the MDU, and the MDU pharmacist then verified that the order was appropriate for the patient and faxed the order to the chemotherapy room. One oncology pharmacist entered the chemotherapy order, and the second oncology pharmacist performed the order-entry check. Two pharmacy technicians set up and prepared the chemotherapy doses, and the second pharmacist was also responsible for checking the final product. After the process change, the CSPT screened the order, and the MDU pharmacist verified that it was correct for the patient. The CSPT then entered the order in the computer in the MDU and faxed the order to the chemotherapy room. The first oncology pharmacist checked the order entry and printed labels, and the second oncology pharmacist checked the final product and label. The new process was thought to improve workflow and safety by allowing chemotherapy orders to be entered in a quiet, dedicated area in the MDU, where patient information was readily available, and by having the 2 oncology pharmacists in the chemotherapy room perform independent checks of the order. Stages that were not affected by the process change were order screening, verification, dose set-up, dose preparation, and final product check, and these were not evaluated for this study.

\section{Data Collection}

In phase 1 (before the process change), data were collected over 7 nonconsecutive days in November 2011 during pharmacist order entry by the traditional method. Data collection for phase 2 (after the process change) took place over 6 nonconsecutive days in May and June 2012, about 2 months after the CSPT had completed training and certification for order entry. These dates were chosen to allow for a variety of staff to be audited and, in phase 2, for the CSPT to become experienced with order entry. The staff (several pharmacists, one CSPT) who participated in the timing studies all had at least 5 years of experience in an oncology setting. Time-and-motion studies were used to measure the time for a pharmacist or a CSPT to enter an order or check order entry; interruptions and errors that were discovered during order processing were documented during these same timeand-motion studies. Industrial engineering students performed the time-and-motion measurements using a personal digital assistant with UMT Plus time study software (Laubrass, Montréal, Quebec), which was customized to the data collection needs of the study. One student spent time with pharmacy staff to develop and pilot the data collection tool, to ensure it worked smoothly, and made revisions as necessary. The student documented the timing procedures and then used the data collection tool to record the data during phase 1. A second student reviewed the timing procedures, spent time with pharmacy staff to become familiar with the workflow, and practised using the personal digital assistant before recording data in phase 2 . The students worked on this project during a 4-month internship program, so the same student was not available for both phases of the study.

The analysis included all parenteral (e.g., intravenous [IV], subcutaneous, intrathecal) chemotherapy orders for patients being treated in the MDU that were entered by the hospital pharmacy for preparation in the biological safety cabinet, including injectable mesna product (which is prepared in the hood but administered orally) and clinical trial medications. Orders for all other oral products for MDU patients and orders for chemotherapy for patients not being treated in the MDU were excluded.

Time-and-motion studies were performed for all orders that met the inclusion criteria on the specified data-collection days. The time required for order entry was defined as the amount of time required to complete the entry of one order. Timing started when the pharmacist or CSPT entered the patient's medical record number in the pharmacy information system and started initial review of the patient profile. Timing was halted when order entry was complete or when the pharmacist or CSPT was interrupted. In the case of an interruption, timing started again 


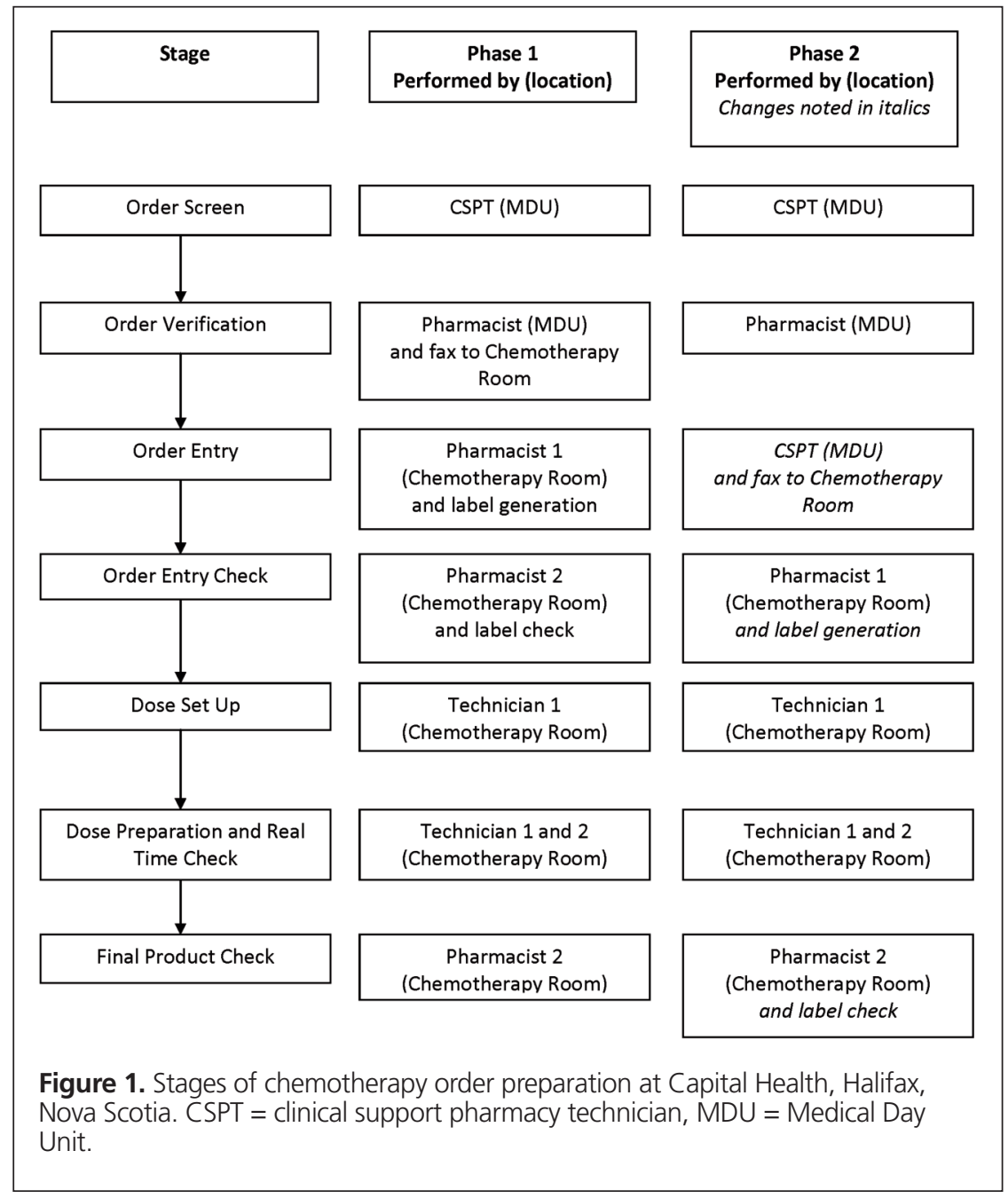

when the interruption ended and order entry resumed. The staff member communicated when tasks changed, to allow for accurate timing by the student observer. For the purpose of timing, an "order" could be an individual medication order or an order set, for which the pharmacy staff member entered multiple orders from a preprinted order at the same time. Such order sets were identified, and the total time to process the order set was divided by the number of orders entered. The time required for order-entry checking was defined as the amount of time to check that one order had been entered correctly in the pharmacy information system. It was not feasible to time each order sequentially from the start of order entry to completion of order-entry checking, as each task was performed in batches, with a time lag in between.

Interruptions in order entry or order-entry checking were counted and timed to determine the duration of the interruption (difference between start and stop time), and the originator of the interruption was documented as "internal" (i.e., interruption initiated by the staff member performing the task) or "external" (i.e., interruption initiated by an outside person). Interruptions included phone calls or questions from (or to) other staff. Interruptions were classified as necessary (core function that added value to the task, such as checking allergies, or that was required to complete the task, such as generating labels) or nonvalue added (not related to the task, such as talking to staff about unrelated matters).

The timing observer also made note of errors that were reported by staff either during the order-entry stage or the orderentry checking stage. Errors identified during order entry were considered to be prescriber errors, and errors identified during order-entry checking indicated errors by the staff member who had performed order entry. Staff reported the errors as missing or incorrect information related to patient name, allergy, body surface area (height, weight), drug, chemotherapy protocol/ regimen, strength, dose, date of administration, drug costing/ funding, physician signature, IV diluents (concentration, volume, expiry), and administration (directions, auxiliary labels, duration of infusion). The severity of both prescriber and order-entry errors was rated using a published scale that has been validated for pharmacist clinical interventions to address 
prescriber errors, but not specifically for chemotherapy orderentry errors. ${ }^{12}$ For each error, the staff member assigned a severity rating of potentially lethal, serious, significant, minor, or no error. ${ }^{12}$ The scale was applied without modification, except that "wrong billing plan" was provided as an additional example for the category of "no error". The severity rating was recorded by the timing observer.

\section{Sample Size}

This was an observational study, and formal sample size calculations were not performed. In an average month, 339 bags and 213 syringes were prepared for the MDU, or about 25 doses every weekday. A convenience sample was determined to be 5 days of data collection or about 125 doses each for both order entry and order-entry checking for phases 1 and 2 (e.g., 250 doses for each phase of the study).

\section{Data Analysis}

All data were entered in Excel software, version 2007 (Microsoft, Redmond, Washington) to provide summary statistics of timing, interruptions, and errors. Timing data for each stage (order entry and order-entry checking) were reported as means with standard deviations and medians with interquartile ranges. The difference in mean time for each task between phases 1 and 2 was tested in Microsoft Excel with a 2-sided unpaired $t$ test, with probability less than 0.05 indicating significance.

\section{RESULTS}

Timing, interruptions, and errors related to order entry are presented in Table 1 for phases 1 and 2. Entry of chemotherapy orders by a CSPT was significantly faster (by $17 \mathrm{~s}$ per order) than entry by the oncology pharmacist (1:20 min versus 1:37 min; $p=0.044$ ). Order entry took an average of $33 \mathrm{~min}$ per day (mean 20.4 orders/day $\times 1: 37 \mathrm{~min} /$ order) in phase 1 and 28:24 min per day (mean 21.3 orders/day $\times 1: 20 \mathrm{~min} /$ order) in phase 2 . Timing, interruptions, and errors related to order-entry checking are shown in Table 2. There was no significant difference in the mean time to complete order-entry checking between phase 1 and phase $2(p=0.69)$. There were fewer interruptions per order in phase 2 for both order entry and order-entry checking. Overall, errors were infrequent and were scored as "no error" on the severity rating scale.

\section{DISCUSSION}

A trained CSPT entered chemotherapy orders slightly faster than the oncology pharmacist, and this process change did not appear to affect the time needed to check chemotherapy orders, nor did it result in more errors. The process change expanded the scope of practice of the pharmacy technician at the study institution and saved the oncology pharmacist about $30 \mathrm{~min}$ per day, which could be used to provide more direct patient care. Medication safety was potentially improved because the pharmacist who checked the final product did so independently from the pharmacist who checked order entry. We hypothesized that interruptions would be reduced if order entry were performed in a quiet work area of the MDU where patient data were readily available. The number of interruptions per order entered appeared to decrease; however, this comparison was not analyzed statistically. At the same time, the duties of the CSPT included answering telephone calls, which contributed to interruptions in phase 2 .

The Embase and PubMed databases were searched, with no restrictions on language or date of publication, using the terms "clinical support pharmacy technician" and "chemotherapy order entry" (as separate searches). These searches yielded no other studies that evaluated chemotherapy order-entry times with which to compare the results of the current study. Furthermore, the absolute measurements from the current study may not be meaningful, because they are dependent on the small sample size and local factors such as the institution's pharmacy information system, staff training, and complexity of the medication regimens.

Despite the fact that pharmacy professional organizations support the expansion of pharmacy technician responsibilities, ${ }^{13,14}$ there have been only a few rigorous evaluations of the effect that specialized pharmacy technician roles have on the efficiency of pharmacy workflow and patient care. Van den Bemt and others ${ }^{7}$ found that pharmacy technicians can assist with medication reconciliation activities by obtaining a best possible medication history from patients scheduled for elective general surgery. This resulted in a significant decrease in medication discrepancies, from $18.6 \%$ to $5.4 \%$ of patients, relative to medication lists prepared by anesthesiologists. The pharmacy technician was also responsible for documenting drug allergies, communicating to the patient about stopping antithrombotics before surgery, and following up with the community pharmacist. ${ }^{7}$

The CSPT role in a Canadian intensive care unit has been described. ${ }^{9}$ In that setting, the CSPT entered patient, medication, and laboratory data on a patient monitoring form, so that the intensive care unit pharmacist had access to up-to-date information. The CSPT also provided other support, such as answering questions about compatibility of IV drugs and solving drug distribution issues. The enhanced efficiency reduced the average time for each assessment from 15 to $10 \mathrm{~min}$ per patient, which allowed the pharmacist to perform additional patient assessments. ${ }^{9}$

Koch and Weeks ${ }^{15}$ described how 2 clinically oriented pharmacy technicians provided data collection and disease screening activities, as well as enhanced tracking of patient outcomes. The 2 full-time technicians in their study screened 
Table 1. Timing Results for Chemotherapy Order Entry*

\begin{tabular}{|c|c|c|}
\hline Result & Phase 1 & Phase 2 \\
\hline \multicolumn{3}{|l|}{ Timing } \\
\hline No. of chemotherapy orders entered & 143 & 128 \\
\hline No. of order sets & 33 & 33 \\
\hline No. of days with auditing & 7 (20.4 orders/day) & 6 (21.3 orders/day) \\
\hline Time per order, mean \pm SD $†$ & $1: 37 \pm 1: 17$ & $1: 20 \pm 1: 02$ \\
\hline Time per order, median (IQR) & $1: 17(0: 57-1: 55)$ & $0: 55(0: 47-1: 25)$ \\
\hline \multicolumn{3}{|l|}{ No. of Interruptions } \\
\hline $\begin{array}{l}\text { Necessary, related to order entry, } \\
\text { no. (total time) }\end{array}$ & $9(9: 49)$ & $10(6: 48)$ \\
\hline $\begin{array}{l}\text { Non-value added, not related to } \\
\text { order entry, no. (total time) }\end{array}$ & $33(39: 38)$ & $25(30: 08)$ \\
\hline Total, no. (no./order) & $42(0.29)$ & $35(0.27)$ \\
\hline Errors, no. & 3 & 0 \\
\hline Severity category & $\begin{array}{l}\text { "No error" } \\
\text { (incorrect date }[n=1], \\
\text { incorrect billing plan } \\
[n=2])\end{array}$ & \\
\hline \multicolumn{3}{|c|}{$\begin{array}{l}\text { IQR = interquartile range, SD = standard deviation. } \\
\text { * Phase } 1 \text { involved a pharmacist performing both order entry and order-entry checking; phase } 2 \\
\text { involved a pharmacy technician performing order entry and a pharmacist performing order-entry } \\
\text { checking. Time data are expressed as minutes:seconds. } \\
\text { †The time per order was significantly different in phase } 1 \text { and phase } 2 \text {, by } 2 \text {-sided unpaired } \\
t \text { test }(p=0.044) \text {. }\end{array}$} \\
\hline
\end{tabular}

Table 2. Timing Results for Chemotherapy Order-Entry Checking*

\begin{tabular}{|c|c|c|}
\hline Result & Phase 1 & Phase 2 \\
\hline \multicolumn{3}{|l|}{ Timing } \\
\hline No. of chemotherapy orders checked & 144 & 122 \\
\hline No. of order sets & 34 & 32 \\
\hline No. of days with auditing & 7 (20.6 orders/day) & 6 (20.3 orders/day) \\
\hline Time per order, mean \pm SD $†$ & $1: 21 \pm 0: 41$ & $1: 20 \pm 0: 28$ \\
\hline Time per order, median (IQR) & $1: 24(1: 04-1: 36)$ & $1: 16(1: 06-1: 23)$ \\
\hline \multicolumn{3}{|l|}{ Interruptions } \\
\hline $\begin{array}{l}\text { Necessary, related to order-entry } \\
\text { checking, no. (total time) }\end{array}$ & $8(1: 34)$ & $5(2: 03)$ \\
\hline $\begin{array}{l}\text { Non-value added, not related to } \\
\text { order-entry checking, no. (total time) }\end{array}$ & $25(8: 38)$ & $16(13: 24)$ \\
\hline Total, no. (no./order) & $33(0.23)$ & $21(0.17)$ \\
\hline Errors, no. & 0 & 1 \\
\hline Severity category & & $\begin{array}{c}\text { "No error" } \\
\text { (incorrect date) }\end{array}$ \\
\hline \multicolumn{3}{|c|}{$\begin{array}{l}\text { IQR = interquartile range, SD = standard deviation. } \\
\text { *Phase } 1 \text { involved a pharmacist performing both order entry and order-entry checking; phase } 2 \\
\text { involved a pharmacy technician performing order entry and a pharmacist performing order-entry } \\
\text { checking. Time data are expressed as minutes:seconds. } \\
\text { †The time per order was not significantly different in phase } 1 \text { and phase } 2, \text { by } 2 \text {-sided unpaired } \\
t \text { test }(p=0.69) \text {. }\end{array}$} \\
\hline
\end{tabular}

about 400 patients per month and, in total, freed up more than 8 hours per day of pharmacist time to provide clinical activities. ${ }^{15}$ In another study, Read and others ${ }^{16}$ reviewed the ability of a pharmacy technician to provide medication reviews and patient counselling in an outpatient breast cancer clinic. The technician completed specialized training in medicines management, chemotherapy support medication, and patient counselling. Patients were randomly assigned to receive usual care or to attend the technician-led clinic. There was a significant increase in patients' knowledge of their medications in the technician group, and a decrease in chemotherapy delays, chemotherapy dose reductions, number of support medications required, and drug costs. ${ }^{16}$ However, the authors of that study did not examine chemotherapy order entry.

The current study had a number of limitations because of its observational, uncontrolled design. The number of orders audited was small, and the results may not be generalizable to other settings. Staff knew that they were being timed, which could have affected their speed. Data collection took place over 2 separate time periods over different durations of time (7 days 
in phase 1 and 6 days in phase 2). Different staff were involved, with varied knowledge and experience, which reduced standardization and introduced more confounding variables that could have influenced the results. As well, the timing observer was different for each phase of the study, which could have introduced measurement error and more variation in the results. Procedures for training and timing were kept consistent during each period to minimize the effect of these factors. Finally, the scale used to rate the severity of errors ${ }^{12}$ was not validated for chemotherapy order entry or checking, which might have reduced the ability of staff to adequately categorize the errors.

\section{CONCLUSION}

This study suggests that a trained CSPT may be able to perform chemotherapy order-entry tasks just as safely and accurately as a pharmacist, although a larger study is needed to confirm this conclusion. The amount of pharmacist time saved by having the CSPT perform chemotherapy order entry may allow the pharmacist to participate in more direct patient care activities. Other potential benefits include better workflow and more efficient use of pharmacy staff. Experience from this centre may help other hospitals in Canada to change their chemotherapy order-entry practice and to expand the pharmacy technician role to meet increasing demands for cancer care.

\section{References}

1. Schwappach DL, Wernli M. Medication errors in chemotherapy: incidence, types and involvement of patients in prevention. A review of the literature. Eur J Cancer Care (Engl). 2010;19(3):285-92.

2. Chung KF, Cheung RC, Tam JW. Long-term benzodiazepine userscharacteristics, views and effectiveness of benzodiazepine reduction information leaflet. Singapore Med J. 1999;40(3):138-43.

3. Gandhi TK, Bartel SB, Shulman LN, Verrier D, Burdick E, Cleary A, et al. Medication safety in the ambulatory chemotherapy setting. Cancer. 2005;104(11):2477-83.

4. Walsh KE, Dodd KS, Seetharaman K, Roblin DW, Herrinton LJ, Von Worley A, et al. Medication errors among adults and children with cancer in the outpatient setting. J Clin Oncol. 2009;27(6):891-6.

5. Standards of practice for oncology pharmacy in Canada. Version 2. North Vancouver (BC): Canadian Association of Pharmacy in Oncology; 2009 [cited 2016 Jan 25]. Available from: www.capho.org/sites/default/files/ page-files/StandardsofPracticeFORWEBV2Dprintable.pdf

6. Myers R, Saulnier L, Gould O. Obtaining the best possible medication history: comparison of pharmacy technician versus pharmacist obtained medication histories in the emergency department [abstract]. Can J Hosp Pharm. 2010;63(1):80.

7. van den Bemt PM, van den Broek S, van Nunen AK, Harbers JB, Lenderink AW. Medication reconciliation performed by pharmacy technicians at the time of preoperative screening. Ann Pharmacother. 2009;43(5):868-74.

8. Mark SM, Saenz R, Yourich BE, Weber RJ. Innovative roles for pharmacy technicians: developing and implementing a unit-based clinical support pharmacy technician model. Hosp Pharm. 2008;43(11):920-7.
9. Mabasa VH, Malyuk DL, Tung A, Balen RM, Nicolls TR, Rahiman NL. Using clinical pharmacy support technicians to optimize pharmaceutical care in the intensive care unit. Can J Hosp Pharm. 2010;63(1):41-5.

10. Kalman MK, Witkowski DE, Ogawa GS. Increasing pharmacy productivity by expanding the role of pharmacy technicians. Am J Hosp Pharm. 1992; 49(1):84-9.

11. Lo A, Co M, Lo C, Chua D, Soltesz D. Specialized pharmacy oncology technician: experience at the Ridge Meadows Hospital. Can J Hosp Pharm. 2010;63(2):138-41.

12. Overhage JM, Lukes A. Practical, reliable, comprehensive method for characterizing pharmacists' clinical activities. Am J Health Syst Pharm. 1999; 56(23):2444-50.

13. McGregor K, Millin B, Aro S, Samuelson A. An information paper on the role of the pharmacy technician. Can J Hosp Pharm. 2001;54(4):293-6.

14. Academy of Managed Care Pharmacy; American Association of Colleges of Pharmacy; American College of Apothecaries; American College of Clinical Pharmacy; American Council on Pharmaceutical Education; American Pharmaceutical Association; et al. White paper on pharmacy technicians (2002): needed changes can no longer wait. J Am Pharm Assoc (Wash). 2003; 43(1):93-107.

15. Koch KE, Weeks A. Clinically oriented pharmacy technicians to augment clinical services. Am J Health Syst Pharm. 1998;55(13):1375-81.

16. Read H, Ladds S, Rhodes B, Brown D, Portlock J. The impact of a supplementary medication review and counselling service within the oncology outpatient setting. Br J Cancer. 2007;96(5):744-51.

Heather Neville, BScPharm, MSc, is a Drug Utilization Pharmacist and Pharmacy Research Coordinator with the Central Zone (formerly Capital Health), Nova Scotia Health Authority, Halifax, Nova Scotia.

Larry Broadfield, BSCPharm, MHSc, FCSHP, is Manager of the Systemic Therapy Program, Cancer Care Nova Scotia, and Clinical Co-ordinator for Oncology Pharmacy with the Central Zone, Nova Scotia Health Authority, Halifax, Nova Scotia.

Claudia Harding, BScPharm, is Clinical Pharmacy Manager for Oncology, Surgery and Research with the Central Zone, Nova Scotia Health Authority, Halifax, Nova Scotia.

Shelley Heukshorst is a Clinical Support Pharmacy Technician (Hematology) with the Central Zone, Nova Scotia Health Authority, Halifax, Nova Scotia.

Jennifer Sweetapple, BSCPharm, ACPR, is a Clinical Pharmacist (Hematology) with the Central Zone, Nova Scotia Health Authority, Halifax, Nova Scotia.

Megan Rolle, BSCPharm, ACPR, is a Clinical Pharmacist (Hematology) with the Central Zone, Nova Scotia Health Authority, Halifax, Nova Scotia.

Competing interests: None declared.

\section{Address correspondence to:}

Heather Neville

Central Zone, Nova Scotia Health Authority

Room 2043, 1276 South Park Street

Halifax NS B3H 2 Y9

e-mail: Heather.neville@nshealth.ca

Funding: None received.

Acknowledgement: The authors wish to thank the engineering students for conducting the time-and-motion studies. 